\title{
Regression Mathematical Model of China Electronic Commerce Transaction Scale Based on Information Reused Analysis Method
}

\author{
Shiqiang Zhang, Xuexia Wei \\ Medical Information College, Chongqing Medical University, Chongqing, China \\ Email: math808543@sina.com
}

Received 23 November 2015; accepted 26 February 2016; published 1 March 2016

\begin{abstract}
A regression mathematical model of China electronic commerce transaction scale was given based on information reused analysis method. This regression mathematical model could evaluate and predict change tendency of the China electronic commerce transaction volume and could provide reference for electronic commerce transaction researchers.
\end{abstract}

\section{Keywords}

Trading Volume, Regression, Mathematical Model, Information Reused Analysis Method, Electronic Commerce

\section{Introduction}

Electronic commerce is the use of computer technology and network technology in business activities. Electronic commerce industry has the advantages of the market globalization, the transaction continuity, the low cost, the intensive resources and so on. Nowadays, electronic commerce has become one of the main forms of commodity transaction, and it is the main mode of national economic growth and the future development directions of information society.

China's electronic commerce industry is developing rapidly, the scale of the industry is rapidly expanding, the electronic commerce information, trade and technology and other service enterprises continue to emerge.2009 China's electronic commerce market transactions reached 3.7 trillion yuan.2010 China's electronic commerce market transactions reached 4.5 trillion yuan. 2011 China's electronic commerce market transactions reached 6 trillion yuan. 2012 China's electronic commerce market transactions reached 7.85 trillion yuan. 2013 China's electronic commerce market transactions reached 10.5 trillion yuan. 2014 China's electronic commerce market transactions reached 13.4 trillion yuan [1].

In the era of big data, it is important to find out the information hiding behind the data. Based on these data, a regression mathematical model of China electronic commerce transaction scale was given based on information 
reused analysis method [2].

\section{The Brief Introduction of the Information Reused Analysis Method}

Hypothesis $t=\left\{t_{1}, t_{2}, \cdots, t_{n}\right\}$ indicates time series, the original data sequence corresponding to the time series is $x^{(0)}=\left\{x^{(0)}\left(t_{1}\right), x^{(0)}\left(t_{2}\right), \cdots, x^{(0)}\left(t_{n}\right)\right\}$. The differential operation of time series $t=\left\{t_{1}, t_{2}, \cdots, t_{n}\right\}$ is $\Delta t_{k}=t_{k}-t_{k-1}$, when differential $\Delta t_{k}=$ const, the original data sequence $x^{(0)}=\left\{x^{(0)}\left(t_{1}\right), x^{(0)}\left(t_{2}\right), \cdots, x^{(0)}\left(t_{n}\right)\right\}$ is equal-space sequence. When differential $\Delta t_{k} \neq$ const, the original data sequence $x^{(0)}=\left\{x^{(0)}\left(t_{1}\right), x^{(0)}\left(t_{2}\right), \cdots, x^{(0)}\left(t_{n}\right)\right\}$ is non-equal-space sequence. According to the grey system theory [3] One-accumulated generate sequence of the original data sequence $x^{(0)}=\left\{x^{(0)}\left(t_{1}\right), x^{(0)}\left(t_{2}\right), \cdots, x^{(0)}\left(t_{n}\right)\right\}$ is $x^{(1)}=\left\{x^{(1)}\left(t_{1}\right), x^{(1)}\left(t_{2}\right), \cdots, x^{(1)}\left(t_{n}\right)\right\}$, where in

$$
\left\{\begin{array}{c}
x^{(1)}\left(t_{1}\right)=x^{(0)}\left(t_{1}\right) \\
x^{(1)}\left(t_{k}\right)=x^{(1)}\left(t_{1}\right)+\sum_{i=2}^{k} x^{(0)}\left(t_{i}\right) \Delta t_{i} \\
k=2,3, \cdots, n
\end{array}\right.
$$

When sequence $x^{(1)}=\left\{x^{(1)}\left(t_{1}\right), x^{(1)}\left(t_{2}\right), \cdots, x^{(1)}\left(t_{n}\right)\right\}$ was close to nonhomogeneous exponential law change, the solution $x^{(1)}(t)$ of differential Equation (2) was called the response function.

$$
\left\{\begin{array}{c}
\frac{d x^{(1)}(t)}{d t}+a x^{(1)}(t)=b \\
x^{(1)}\left(t_{1}\right)=x^{(0)}\left(t_{1}\right)
\end{array}\right.
$$

This response function $x^{(1)}(t)$ was

$$
x^{(1)}(t)=\left(x^{(0)}\left(t_{1}\right)-\frac{b}{a}\right) e^{-a\left(t-t_{1}\right)}+\frac{b}{a} .
$$

In response function $x^{(1)}(t)$, the constants $a$ and $b$ were called uncertain parameters. Discrete response function $x^{(1)}(t)$ of the differential Equation (2) was

$$
\left\{\begin{array}{c}
x^{(1)}\left(t_{1}\right)=x^{(0)}\left(t_{1}\right) \\
x^{(1)}\left(t_{k}\right)=\left(x^{(0)}\left(t_{1}\right)-\frac{b}{a}\right) e^{-a\left(t_{k}-t_{1}\right)}+\frac{b}{a} \\
k=2,3, \cdots, n
\end{array}\right.
$$

In response function $x^{(1)}(t)$, for determining constants $a$ and $b$, we could use differential operation of difference Equation (2). That is

$$
\left\{\begin{array}{c}
\frac{\Delta x^{(1)}\left(t_{k}\right)}{\Delta t_{k}}+a x^{(1)}\left(t_{k}\right)=b \\
x^{(1)}\left(t_{1}\right)=x^{(0)}\left(t_{1}\right)
\end{array}\right.
$$

In differential operation (4), we could get

$$
\frac{\Delta x^{(1)}\left(t_{k}\right)}{\Delta t_{k}}=\frac{x^{(1)}\left(t_{k}\right)-x^{(1)}\left(t_{k-1}\right)}{t_{k}-t_{k-1}}=x^{(0)}\left(t_{k}\right) .
$$

In differential operation (4), let $\lambda \in[0,1]$, smoothing $x^{(1)}\left(t_{k}\right)$ of differential Equation (4) by formula $z^{(1)}\left(t_{\mathrm{k}}\right)=$ $\lambda x^{(1)}\left(t_{\mathrm{k}}\right)+(1-\lambda) x^{(1)}\left(t_{\mathrm{k}-1}\right)$, we could get differential equation as follow

$$
\left\{\begin{array}{c}
\frac{\Delta z^{(1)}\left(t_{k}\right)}{\Delta t_{k}}+a z^{(1)}\left(t_{k}\right)=b \\
z^{(1)}\left(t_{1}\right)=x^{(0)}\left(t_{1}\right)
\end{array}\right.
$$

In above differential Equation (5), $\lambda$ was called as background parameters and $z^{(1)}\left(t_{k}\right)$ was called as background value At present, there is still no optimum getter for background parameters $\lambda$, in order to be used simply and easily, we generally take background parameters for 1/2 in reference [3].

Substituting one-accumulated generate sequence of original sequence $x^{(0)}=\left\{x^{(0)}\left(t_{1}\right), x^{(0)}\left(t_{2}\right), \cdots, x^{(0)}\left(t_{n}\right)\right\}$ into above differential equation, with matrix equation $a$ and $b$ could be $[a b]^{T}=\left(B^{T} B\right)^{-1} B^{T} Y$ determined, inside $Y=$ 


$$
\left[x^{(0)}\left(t_{2}\right), x^{(0)}\left(t_{3}\right), \cdots, x^{(0)}\left(t_{n}\right)\right]^{T} \text {, and }
$$

$$
B^{T}=\left[\begin{array}{cccc}
-z^{(1)}\left(t_{2}\right) & -z^{(1)}\left(t_{3}\right) & \cdots & -z^{(1)}\left(t_{n}\right) \\
1 & 1 & \cdots & 1
\end{array}\right]
$$

Substituting obtained parameters $a$ and $b$ into differential operation (4), we could get traditional GM(1.1) model of sequence $x^{(0)}=\left\{x^{(0)}\left(t_{1}\right), x^{(0)}\left(t_{2}\right), \cdots, x^{(0)}\left(t_{n}\right)\right\}$ :

$$
\left\{\begin{array}{l}
\hat{x}^{(0)}\left(t_{1}\right)=x^{(0)}\left(t_{1}\right) \\
\hat{X}^{(0)}\left(t_{k}\right)=\frac{\hat{x}^{(1)}\left(t_{k}\right)-\hat{x}^{(1)}\left(t_{k-1}\right)}{t_{k}-t_{k-1}} \\
\hat{x}^{(1)}\left(t_{k}\right)=\left(x^{(0)}\left(t_{1}\right)-\frac{b}{a}\right) e^{-a\left(t_{k}-t_{1}\right)}+\frac{b}{a}
\end{array}\right.
$$

Fitting and forecast precision sometimes of the traditional GM(1.1) model was poor. we put forward a information reused analysis method. Firstly, we could call traditional GM (1.1) model (6) of original sequence $x^{(0)}=$ $\left\{x^{(0)}\left(t_{1}\right), x^{(0)}\left(t_{2}\right), \cdots, x^{(0)}\left(t_{n}\right)\right\}$ as rough model. Then we rewrote third formulas of rough model (6) as follows, wherein, $a$ and $b$ were new uncertain parameters.

$$
\hat{x}^{(1)}\left(t_{k}\right)=\alpha e^{-a\left(t_{k}-t_{1}\right)}+\beta \quad k=2,3, \cdots, n
$$

Third, using the accumulated generate sequence and corresponding time series of original sequence again, substituting the accumulated generate sequence $x^{(1)}=\left\{x^{(1)}\left(t_{1}\right), x^{(1)}\left(t_{2}\right), \cdots, x^{(1)}\left(t_{n}\right)\right\}$ and corresponding time series of original sequence $t=\left\{t_{1}, t_{2}, \cdots, t_{n}\right\}$ into above formula (7), we could determine uncertain parameters $\alpha$ and $\beta$ with matrix equation [4] $[\alpha \beta]^{T}=\left(B^{T} B\right)^{-1} B^{T} Y$, inside $Y=\left[x^{(1)}\left(t_{1}\right), x^{(1)}\left(t_{2}\right), \cdots, x^{(1)}\left(t_{n}\right)\right]^{T}$ and

$$
B^{T}=\left[\begin{array}{cccc}
1 & e^{-a\left(t_{2}-t_{1}\right)} & \cdots & e^{-a\left(t_{n}-t_{1}\right)} \\
1 & 1 & \cdots & 1
\end{array}\right] .
$$

Substituting parameters $\alpha$ and $\beta$ into equation (7), we could get the reducing value of original sequence $x^{(0)}=$ $\left\{x^{(0)}\left(t_{1}\right), x^{(0)}\left(t_{2}\right), \cdots, x^{(0)}\left(t_{n}\right)\right\}$

$$
\left\{\begin{array}{cc}
\hat{\hat{x}}^{(1)}\left(t_{k}\right)=\alpha e^{-a\left(t_{k}-t_{1}\right)}+\beta & (k=1,2, \cdots, n) \\
\hat{x}^{(0)}\left(t_{k}\right)=\frac{\hat{\hat{x}}^{(1)}\left(t_{k}\right)-\hat{\hat{x}}^{(1)}\left(t_{k-1}\right)}{t_{k}-t_{k-1}} & (k=2,3, \cdots, n)
\end{array}\right.
$$

The formula (8) was the regression mathematical model based on information reused analysis method.

\section{Regression Mathematical Model of China Electronic Commerce Transaction Scale}

Table 1 shows the statistical number of the China's electronic commerce market transactions from 2009 to 2014. Data came from China electronic commerce research center website.

According to the statistical number of the China's electronic commerce market transactions from 2009 to 2014 [1], the regression mathematical model based on information reused analysis method as follow

$$
\hat{\hat{x}}^{(1)}\left(t_{k}\right)=14.9585 e^{-0.268\left(t_{k}-t_{1}\right)}-11.343 \quad(k=1,2, \cdots, \text { and } n)
$$

Figure 1 is a diagram of the curve of original trading volume data of the China electronic commerce transaction and its simulation data based on information reused analysis method from 2009 to 2014.

Based on information reused analysis method, we forecasted the number of the trading volume of the China electronic commerce transaction form 2015 to 2018. The simulation data of the trading volume from 2015 to 2018 could be forecasted as in Table 2. Forecast data of the trading volume of the China electronic commerce transaction showed a rapid growth trend.

Figure 2 is a diagram of the curve of simulation data of the forecast data of the trading volume of the China electronic commerce transaction form 2009 to 2018. 


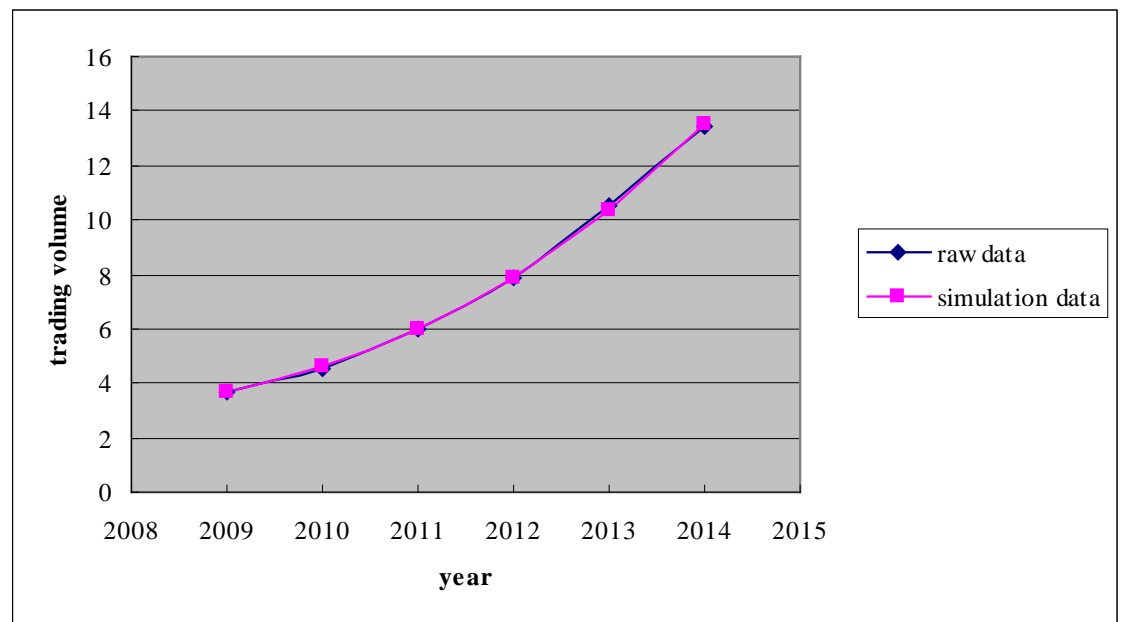

Figure 1. The tendency curve of the trading volume with time.

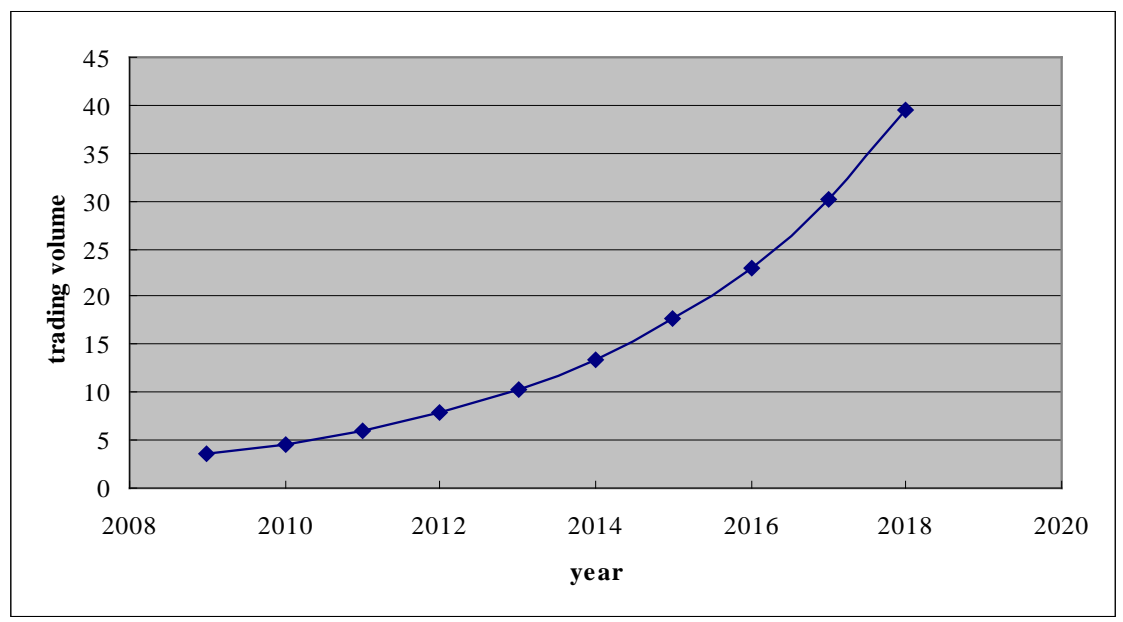

Figure 2. The curve of simulation data of the trading volume from 2009 to 2018.

Table 1. Original data.

\begin{tabular}{cccc}
\hline Time (Year) & Trading volume (trillion yuan) & Time (Year) & Trading volume (trillion yuan) \\
\hline 2009 & 3.70 & 2010 & 4.50 \\
2011 & 6.00 & 2012 & 7.85 \\
2013 & 10.50 & 2014 & 13.40 \\
\hline
\end{tabular}

Table 2. Forecast data of the trading volume.

\begin{tabular}{cccc}
\hline Time (Year) & Trading volume (trillion yuan) & Time (Year) & Trading volume (trillion yuan) \\
\hline 2015 & 17.65 & 2016 & 23.09 \\
2017 & 30.21 & 2018 & 39.52 \\
\hline
\end{tabular}

From 2009 to 2018 the simulation data of the trading volume over time trend graph can be seen that the number of the China's electronic commerce market transactions has gradually from slowly increase to a rapid growth trend. 


\section{Conclusions}

Electronic commerce has become one of the main forms of commodity transaction, and it is the main mode of national economic growth and the future development directions of information society. This paper gives a modeling way based on information reused analysis method. On the one hand, this way based on information reused analysis method greatly improved GM $(1,1)$ model's fitting precision and prediction accuracy; on the other hand, it maintains the advantage of the traditional modeling method which is simple. Based on these data of China electronic commerce transaction scale, a regression mathematical model of China electronic commerce transaction scale was given based on information reused analysis method. The regression mathematical model based on information reused analysis method evaluates and predicts the rading volume trend of the China electronic commerce transaction. Case analysis verified the validity and usefulness of the model based on information reused analysis method [5]. The way based on information reused analysis method could provide reference for electronic commerce transaction researchers.

\section{References}

[1] China Electronic Commerce Research Center Website. http://www.100ec.cn

[2] Zhang, S.Q. (2009) Modeling Method of Grey System GM(1.1) Model Based Information Reused and It’s Application. Mathematics in Practice and Theory, 39, 97-104.

[3] Deng. J.L. (1982) Control Problems of Grey Systems. Systems \& Control Letters, 1, 288-294. http://dx.doi.org/10.1016/S0167-6911(82)80025-X

[4] Zhang, S.Q. and Jiang, Z. (2010) Modeling Method of Logisitic Model Based Grey System. Mathematics in Practice and Theory, 40, 144-148.

[5] Lv, J.N., Zhang, S.Q., Zhang, L. and Jiang, Z. (2010) Grey System GM(1.1) Model Based Information Reused and Its Application on Infectious Disease Trends Forecast. Modern Preventive Medicine, 37, 2601-2603. 